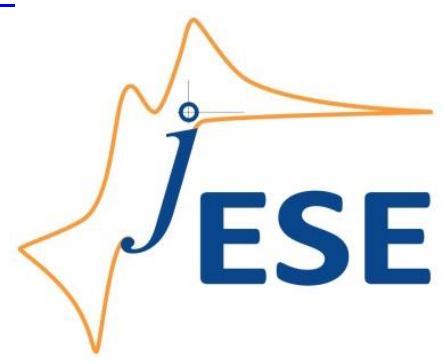

Open Access: ISSN 1847-9286

www.jESE-online.org

Original scientific paper

\title{
Carvacrol electrochemical reaction characteristics on screen printed electrode modified with $\mathrm{La}_{2} \mathrm{O}_{3} / \mathrm{CO}_{3} \mathrm{O}_{4}$ nanocomposite
}

\author{
Sayed Zia Mohammadi ${ }^{1, \bigotimes}$, Hadi Beitollahi ${ }^{2}$, Tahereh Rohani ${ }^{1}$, Hossein Allahabadi ${ }^{1}$ \\ ${ }^{1}$ Department of Chemistry, Payame Noor University, Tehran, Iran \\ ${ }^{2}$ Environment Department, Institute of Science and High Technology and Environmental Sciences, \\ Graduate University of Advanced Technology, Kerman, Iran
}

${ }^{\bowtie}$ Corresponding author: szmohammadi@yahoo.com, Tel.: +98 3433353591, Fax: +98 3433353621

Received: November 16, 2018; Revised: January 15, 2019; Accepted: January 17, 2019

\begin{abstract}
Electrochemical characteristics of carvacrol were investigated on a screen-printed electrode (SPE) modified with $\mathrm{La}_{2} \mathrm{O}_{3} / \mathrm{CO}_{3} \mathrm{O}_{4}$ nanocomposite by using voltammetric techniques, which displayed a well-defined peak for sensitive carvacrol determination in phosphate buffer solution (PBS) at $\mathrm{pH}$ 7.0. $\mathrm{La}_{2} \mathrm{O}_{3} / \mathrm{CO}_{3} \mathrm{O}_{4}$ nanoparticles demonstrated suitable catalytic activity for carvacrol determination by differential pulse voltammetry (DPV) technique. Besides, determination of carvacrol in a real samples was recognized in the light of electrochemical findings and a validated voltammetric technique for quantitative analysis of carvacrol in a real formulation was proposed. The DPV peak currents were found to be linear in the concentration range of 10.0 to $800.0 \mu \mathrm{M}$. The limit of detection (LOD) was found to be $1.0 \mu \mathrm{M}$.
\end{abstract}

\section{Keywords}

Carvacrol, electrochemical reaction, $\mathrm{La}_{2} \mathrm{O}_{3} / \mathrm{CO}_{3} \mathrm{O}_{4}$ nanocomposite, differential pulse voltammetry

\section{Introduction}

Carvacrol (5-isopropyl-2-methylphenol) is the main thyme oil constituent, crucial oil of Origanum vulgare, and plants including Thymus vulgaris [1]. This compound is an ordinary additive applied in numerous foods (as flavorings), pharmaceuticals and perfumes due to its antitussive, anticarcinogenic, antioxidant, antibacterial, anticancer and antifungal features [2-5]. As the standardization of pharmaceutical compounds is based on their carvacrol content, the development of a novel validated technique for its quantification is a challenging requirement $[6,7]$.

Numerous analytical methods such as gas chromatography (GC), thin-layer chromatography (TLC) combined with densitometry, gas chromatography-mass spectrometry (GC-MS) and highperformance liquid chromatography (HPLC) with fluorimetric detection have been employed for carvacrol measurement in many matrixes [8-11]. In some cases, lower content of carvacrol in 
complicated matrices makes an emergency task to the preliminary application of preconcentration and separation procedures [12]. As compared with above mentioned methods, which typically require time-consuming and complex sample pretreatment procedure involving separation, extraction, and adsorption, electrochemical sensors have been documented as more authoritative tools [13-16]. The advantages of electrochemical sensors are the possibility of miniaturization and portability, selectivity, sensitivity, a wide linear range, minimal space and power requirement and cost-effective instrumentation. Electrochemical sensors have a leading position among all currently accessible sensors that have already reached the commercial stage and found a vast range of important applications in the fields of clinical, industrial, environmental and agricultural analyses $[17,18]$.

Compared with bare electrodes, modified electrodes have some advantages. Initially, the analyte overpotential can be decreased together with the possible interfering background current. Secondly, the current signal response can be improved and therefore, a lower detection limit can be attained. Thirdly, adsorption of analytes and products can be omitted [19-22]. Consequently, the sensitivity and selectivity of the analysis by using modified electrodes can be significantly increased $[23,24]$. In addition, nanomaterial-modified electrodes have many benefits over traditional material-modified electrodes [25]. Firstly, nanomaterials ensure the vast specific surface area for carvacrol determination on the electrodes. Secondly, some semiconductor nanomaterials, especially metal oxides, may act as promoters of electrochemical communication, accelerating the electron transfer rate between active sites and electrodes. Thirdly, nanomaterials can assist the electrode to preserve its characteristics for a long period of time [26]. So, a variety of nanomaterials have been synthesized and characterized for the electrochemical analysis [27-32].

Nanostructured materials are one of the most promising supporting materials for surface modification of electrodes, due to their unique properties, such as good biocompatibility, high surface-to-volume ratio, enhanced magnetic and electrical properties. Metal oxides of the nanometer size exploited in nanomaterial-modified electrodes for electroanalysis, have some distinct advantages such as low influence of the solution resistance, high mass transport rate, low detection limit and better signal-tonoise ratio compared to the conventional electrodes [33-38]. Thus, $\mathrm{La}_{2} \mathrm{O}_{3} / \mathrm{Co}_{3} \mathrm{O}_{4}$ nanocomposite has already been employed for carvacrol sensor transducer surface which facilitates the electron transfer, enhances the effective electroactive surface area and improves the carvacrol detection limit.

Nowadays, application of screen-printed electrodes (SPEs) for analyte analysis is in the main research focus in electrochemical sensors area, what is due to their reliability, mass production, reproducibility, and low cost [39]. As ductile devices, SPEs can be drawn in different shapes and made from various materials [40]. This study will focus on the design and fabrication of disposable SPE modified with $\mathrm{La}_{2} \mathrm{O}_{3} / \mathrm{CO}_{3} \mathrm{O}_{4}$ nanocomposite for electrochemical detection of carvacrol. Special emphasis will be put on the sensor fabrication procedure, operating details and performance characteristics for carvacrol monitoring. Electrochemical properties of fabricated sensor propose sensitive voltammetric determination of carvacrol with advantages of low detection limit, respectable stability and rapid response towards electro-oxidation of carvacrol compared to bare SPE. To the best of our knowledge, this investigation is the first report describing the application of SPE modified with nanoparticles for carvacrol determination in real-samples.

\section{Experimental}

\section{Reagents}

Carvacrol was purchased from Sigma-Aldrich (Tulsa, OK, USA). Sodium dihydrogen phosphate, sodium monohydrogen phosphate, orthophosphoric acid and sodium hydroxide were provided 
from Merck (Darmstadt, Germany). Doubly distilled, deionized water was employed in all experiments. All other chemicals exploited in this study were of analytical reagent grade and purchased from Merck (Darmstadt, Germany). Stock solutions of carvacrol were prepared by dissolving the appropriate compound amount in acetonitrile. Working solutions were prepared by accurate dilution from stock solutions of these compounds using phosphate buffer solution (PBS). PBS was employed as the supporting electrolyte.

\section{Apparatus}

The SPE (DropSens, DRP-110, Spain) consists of three main parts which are silver pseudoreference electrode, graphite counter electrode, and graphite working electrode, respectively. Voltammetric measurements (cyclic voltammetry and differential pulse voltammetry) were done using a potentiostat/galvanostat (PGSTAT 302N, Autolab, Eco-Chemie, The Netherlands) with the software GPES, version 4.9. Metrohm $710 \mathrm{pH}$ meter, equipped with the glass electrode, was used for $\mathrm{pH}$ measurements.

The surface morphology of the composites was analyzed with KYKY, EM 3200 scanning electron microscopy (SEM). XRD studied were conducted on a Rigaku D/max $2500 \mathrm{~V}$ instrument with a graphite monochromator and a Cu target. The FT-IR spectrophotometer used for the studies was a Bruck Equinox 55 and $\mathrm{KBr}$ pellet technique was used for loading the samples into the instrument.

\section{$\mathrm{La}_{2} \mathrm{O}_{3} / \mathrm{CO}_{3} \mathrm{O}_{4}$ nanocomposite synthesis}

All chemicals used for the preparation of the nano-powders, namely cobalt acetate $\left(\mathrm{Co}\left(\mathrm{CH}_{3} \mathrm{COO}\right)_{2} .2 \mathrm{H}_{2} \mathrm{O}\right)$, thiourea $\left(\left(\mathrm{NH}_{2}\right)_{2} \mathrm{CS}\right)$ and ammonia $\left(25 \% \mathrm{NH}_{3}\right)$, were of analytical grade. All the precursors were dissolved in deionized water. During the preparation of the nano-powders, ammonia was used as a complexing agent. $\mathrm{CO}_{3} \mathrm{O}_{4}$ nanostructures were prepared by dissolving $0.46 \mathrm{~mol}$ of cobalt acetate in $80 \mathrm{~mL}$ of deionized water, $0.18 \mathrm{~mol}$ of thiourea in $80 \mathrm{~mL}$ of deionised water and lastly by adding $19.76 \mathrm{~mL}$ of ammonia in $80 \mathrm{~mL}$ of deionised water. The amount of solutions of cobalt acetate, thiourea and ammonia was held constant at a ratio of 1:1:1. Then the cobalt acetate solution was added in a beaker in the reaction bath, followed by adding thiourea solution in the same reaction bath and the mixture was stirred for few seconds. Lastly, ammonia solution was added slowly into the mixture, while continuing stirring for $5 \mathrm{~min}$. The temperature of the bath was then allowed to increase up to $80^{\circ} \mathrm{C}$. After the precipitates were formed, they were left overnight and filtered thereafter. The precipitates were then washed with ethanol. The obtained powders were dried at ambient conditions for several days.

$\mathrm{La}_{2} \mathrm{O}_{3} / \mathrm{CO}_{3} \mathrm{O}_{4}$ nanocomposites were prepared by $\mathrm{La}_{2} \mathrm{O}_{3}$ nanoparticles onto the surface of the $\mathrm{Co}_{3} \mathrm{O}_{4}$ hexagonal nanosheets. A solution of $0.2 \mathrm{~mol}$ of $\mathrm{La}\left(\mathrm{NO}_{3}\right)_{3}, 6 \mathrm{H}_{2} \mathrm{O}(50 \mathrm{~mL})$ was mixed with $0.1 \mathrm{~g}$ $\mathrm{Co}_{3} \mathrm{O}_{4}$ hexagonal nanosheets. Then appropriate amount of $\mathrm{NaOH}$ solution $(1.5 \mathrm{M})$ was added dropwise into the solution until the $\mathrm{pH}$ value of the mixture reached to 10 . The precipitate was brought to a reaction temperature of $80{ }^{\circ} \mathrm{C}$ and stirred for $1 \mathrm{~h}$. After the reaction was completed and cooled to room temperature, the resulting products were centrifuged for $15 \mathrm{~min}$ at $3000 \mathrm{rpm}$. Finally, the precipitate was washed several times with water and vacuum dried at $60{ }^{\circ} \mathrm{C}$ overnight. The obtained black precipitate was $\mathrm{La}_{2} \mathrm{O}_{3} / \mathrm{CO}_{3} \mathrm{O}_{4}$ nanocomposite and was ready for use.

\section{Real samples preparation}

Urine samples were retained in a refrigerator immediately after collection. $10 \mathrm{~mL}$ of the samples were centrifuged for $15 \mathrm{~min}$ at $2000 \mathrm{rpm}$. The supernatant was filtered out by using a $0.45 \mu \mathrm{m}$ filter. Next, different volumes of the solution were transferred to a $25 \mathrm{~mL}$ volumetric flask and diluted to the mark 
with PBS (pH 7.0). The diluted urine samples were spiked with different amounts of carvacrol. The carvacrol contents were analysed by the proposed method and standard addition procedure.

\section{SPE electrode fabrication}

The bare screen-printed electrode was coated with $\mathrm{La}_{2} \mathrm{O}_{3} / \mathrm{CO}_{3} \mathrm{O}_{4}$ nanocomposite, as exposed in the following. The stock solution of $\mathrm{La}_{2} \mathrm{O}_{3} / \mathrm{CO}_{3} \mathrm{O}_{4}$ nanocomposite in $1 \mathrm{~mL}$ of the aqueous solution was prepared by dispersing $1 \mathrm{mg}$ of $\mathrm{La}_{2} \mathrm{O}_{3} / \mathrm{CO}_{3} \mathrm{O}_{4}$ nanocomposite with ultrasonication for $1 \mathrm{~h}$, while $2 \mu \mathrm{l}$ of aliquots of $\mathrm{La}_{2} \mathrm{O}_{3} / \mathrm{Co}_{3} \mathrm{O}_{4} / \mathrm{H}_{2} \mathrm{O}$ suspension solution was cast on the carbon working electrodes, followed by waiting until the solvent was evaporated at $25^{\circ} \mathrm{C}$.

\section{Results and discussion}

\section{Nanostructures characterization}

Figure 1 displays the FT-IR spectrum of $\mathrm{La}_{2} \mathrm{O}_{3} / \mathrm{Co}_{3} \mathrm{O}_{4}$ nanocomposite sample in the frequency range of $400-4000 \mathrm{~cm}^{-1}$. The FT-IR spectrum of $\mathrm{La}_{2} \mathrm{O}_{3} / \mathrm{CO}_{3} \mathrm{O}_{4}$ nanocomposite shows strong vibrational bands in the lower frequency regions (at around 520 and $449 \mathrm{~cm}^{-1}$ ), ascribable to the vibration of metal-O. The absorption seen at $3417 \mathrm{~cm}^{-1}$ is thought to be due to the symmetric vibration of the $-\mathrm{OH}$ groups of absorbed $\mathrm{H}_{2} \mathrm{O}$ molecules [41].

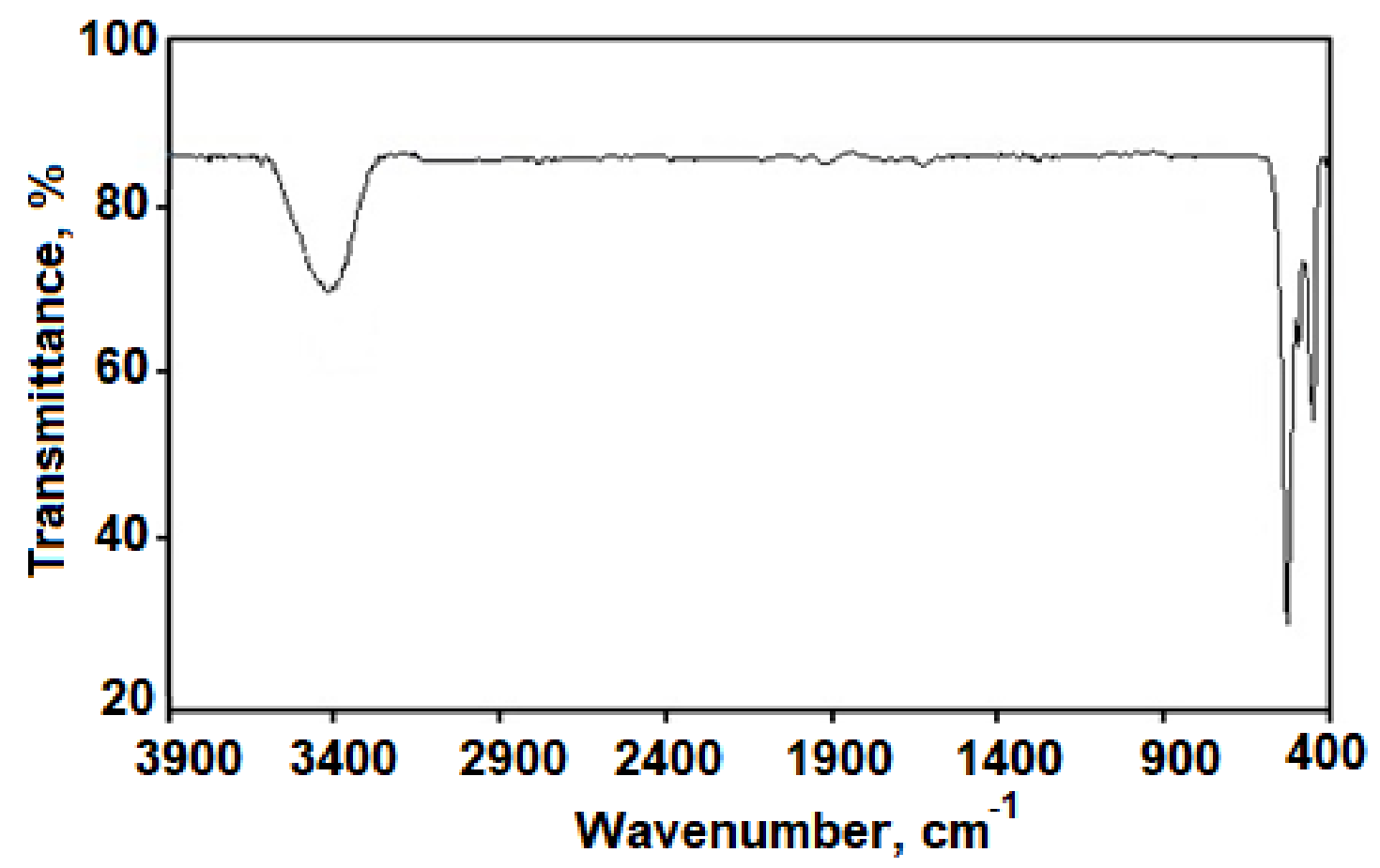

Fig. 1. FT-IR image of $\mathrm{La}_{2} \mathrm{O}_{3} / \mathrm{CO}_{3} \mathrm{O}_{4}$ nanocomposite

From the X-ray diffraction (XRD) pattern of $\mathrm{La}_{2} \mathrm{O}_{3} / \mathrm{CO}_{3} \mathrm{O}_{4}$ nanocomposite shown in Figure 2, it can be seen that all major diffraction peaks match well with the standard peak of this sample. For $\mathrm{La}_{2} \mathrm{O}_{3} / \mathrm{CO}_{3} \mathrm{O}_{4}$ nanocomposite, diffraction peaks at 31.7, 36.1, 44.5, 59.9 and 64.9 ${ }^{\circ}$ (JCPDS 74-2120) can be indexed to (220), (311), (400), (511) and (400) planes of $\mathrm{Co}_{3} \mathrm{O}_{4}$, while diffraction peaks at 15.1, 28.5, 29.1, 39.8, 49.1 and 55.2 (JCPDS 41-4019) can be indexed to (100), (002), (101), (102), (211) and (201) plane of $\mathrm{La}_{2} \mathrm{O}_{3}$, respectively $[42,43]$.

The morphology of the product was examined by SEM. Figure 3 shows that $\mathrm{Co}_{3} \mathrm{O}_{4}$ nanosheets and $\mathrm{La}_{2} \mathrm{O}_{3}$ nanoparticles constitute $\mathrm{La}_{2} \mathrm{O}_{3} / \mathrm{CO}_{3} \mathrm{O}_{4}$ nanocomposite. 


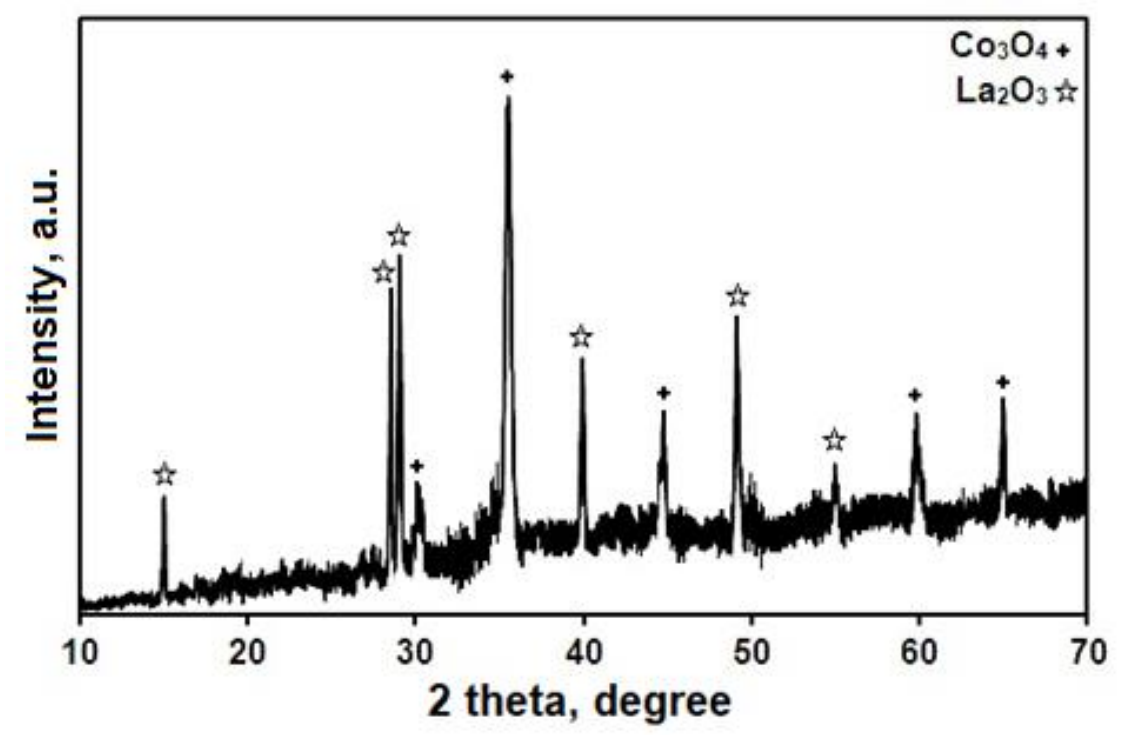

Fig. 2. XRD pattern of $\mathrm{La}_{2} \mathrm{O}_{3} / \mathrm{CO}_{3} \mathrm{O}_{4}$ nanocomposite

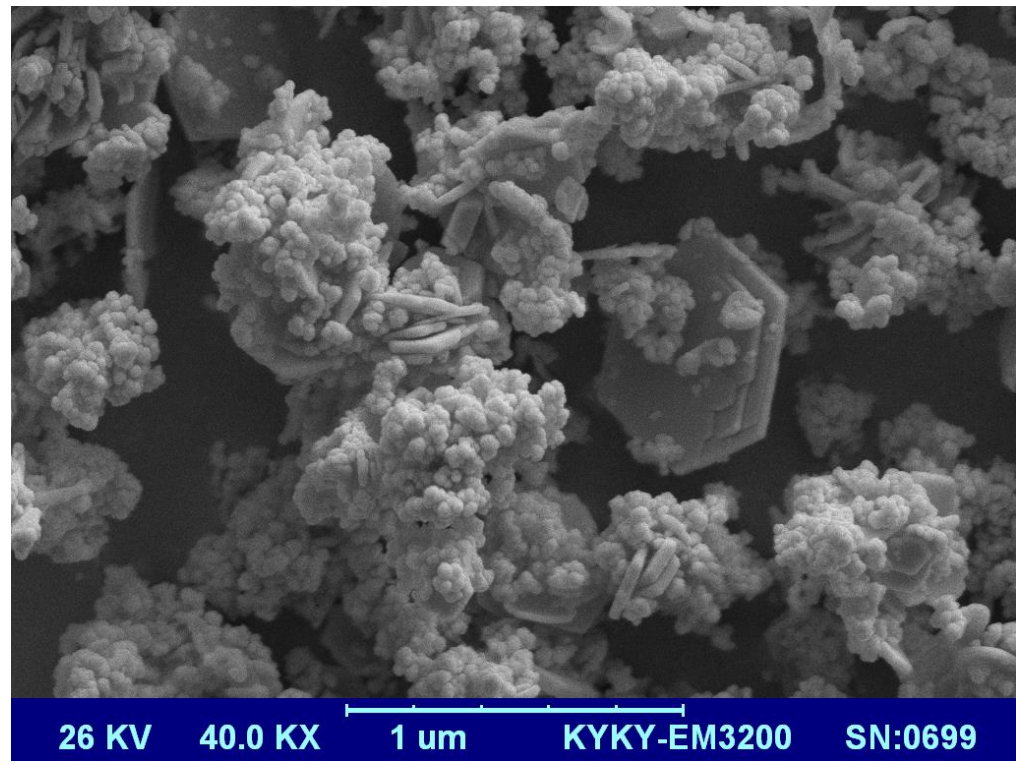

Fig. 3. SEM image of $\mathrm{La}_{2} \mathrm{O}_{3} / \mathrm{CO}_{3} \mathrm{O}_{4}$ nanocomposite.

\section{Electrochemical behaviour of fabricated sensor}

The $\mathrm{pH}$ value of the aqueous solution is effective on the electrochemical behaviour of carvacrol. Therefore, $\mathrm{pH}$ of the solution was optimized to obtain highly accurate results for carvacrol electrooxidation. Accordingly, the electrochemical behaviour of carvacrol at the surface of $\mathrm{La}_{2} \mathrm{O}_{3} / \mathrm{CO}_{3} \mathrm{O}_{4} / \mathrm{SPE}$ was studied by voltammetry in $0.1 \mathrm{M} \mathrm{PBS}$ at $\mathrm{pH}$ values between 2.0 and 9.0. It was revealed that neither acidic nor basic medium was appropriate for the electro-oxidation of carvacrol at the surface of $\mathrm{La}_{2} \mathrm{O}_{3} / \mathrm{CO}_{3} \mathrm{O}_{4} / \mathrm{SPE}$ and best results were obtained at neutral conditions. Accordingly, the $\mathrm{pH} 7.0$ was chosen as the optimum $\mathrm{pH}$ for electro-oxidation of carvacrol at the surface of $\mathrm{La}_{2} \mathrm{O}_{3} / \mathrm{CO}_{3} \mathrm{O}_{4} / \mathrm{SPE}$.

Figure 4 demonstrates the $\mathrm{CV}$ responses for electro-oxidation of $400.0 \mu \mathrm{M}$ carvacrol at $\mathrm{La}_{2} \mathrm{O}_{3} / \mathrm{CO}_{3} \mathrm{O}_{4} / \mathrm{SPE}$ (curve a) and unmodified SPE (curve b). The peak potential corresponding to the carvacrol oxidation occurs at $400 \mathrm{mV}$, which is about $180 \mathrm{mV}$ more negative than for the unmodified SPE. Likewise, the anodic peak current for the oxidation of carvacrol at $\mathrm{La}_{2} \mathrm{O}_{3} / \mathrm{Co}_{3} \mathrm{O}_{4} / \mathrm{SPE}$ is much higher in comparison with the unmodified SPE, indicating thus effectiveness of SPE modification with $\mathrm{La}_{2} \mathrm{O}_{3} / \mathrm{CO}_{3} \mathrm{O}_{4}$ nanocomposite in the carvacrol oxidation process. Based on the obtained results, the oxidation of carvacrol at the surface of $\mathrm{La}_{2} \mathrm{O}_{3} / \mathrm{CO}_{3} \mathrm{O}_{4} / \mathrm{SPE}$ can be considered as a simple 
electrochemical reaction. Also, the effect of potential scan rates on the oxidation current of carvacrol was assessed and shown in Figure 5. According to the results, increase of the potential scan rate causes an increment in the peak current. The linear relationship between anodic peak current $\left(I_{p}\right)$ and the square root of the potential scan rate $\left(v^{1 / 2}\right)$ during the oxidation of carvacrol demonstrates that the oxidation process is under the control of diffusion (Fig. 5). From rising sections of the current-voltage curve recorded at $10 \mathrm{mV} \mathrm{s}^{-1}$, the Tafel curve of analyte is constructed and plotted $n$ Figure 6 . The kinetics of electron transfer in the electrode reactions influences Tafel regions of the current-potential curve. The estimated Tafel slope is $0.1583 \mathrm{~V}$ implying that the rate of electrode process is determined by the electron transfer step (RDS) with charge transfer coefficient $(\alpha)$ of 0.63 [44].

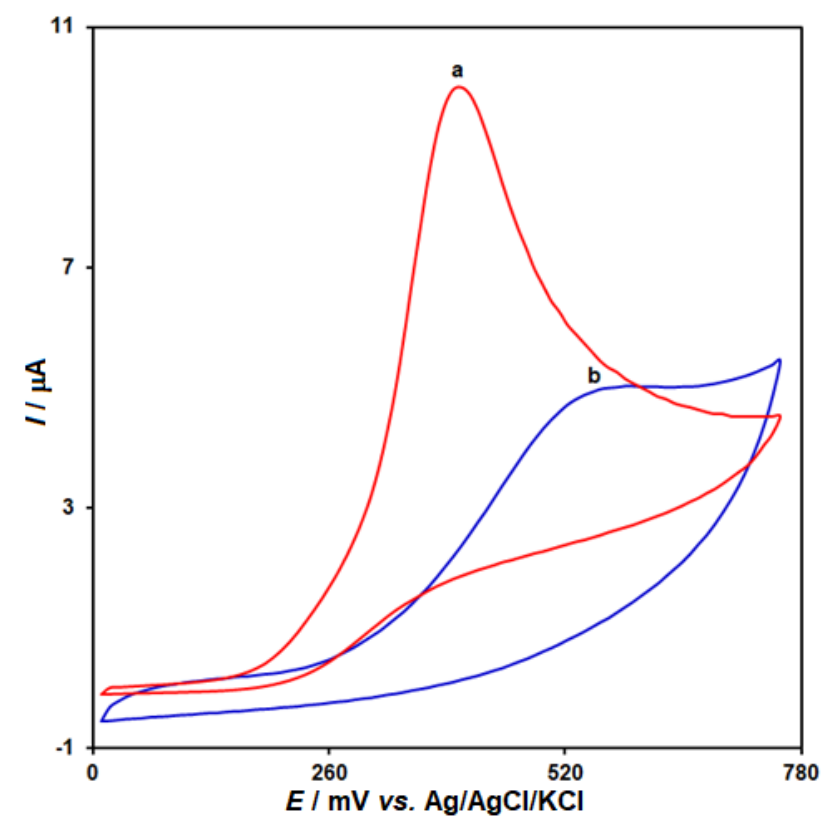

Fig. 4. CVs of $\mathrm{La}_{2} \mathrm{O}_{3} / \mathrm{CO}_{3} \mathrm{O}_{4} / \mathrm{SPE}$ (a) and unmodified SPE (b) in $0.1 \mathrm{MPBS}(\mathrm{pH}$ 7.0) containing $400.0 \mu \mathrm{M}$ CA. Scan rate $=50 \mathrm{mV} \mathrm{s}^{-1}$

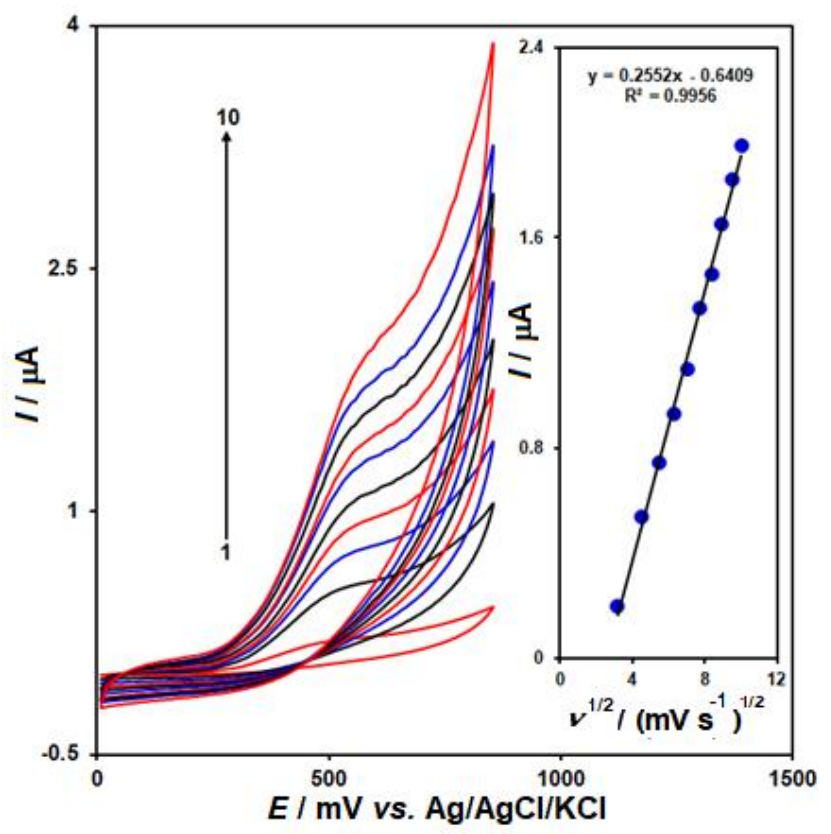

Fig. 5. $\mathrm{CVs}$ of $\mathrm{La}_{2} \mathrm{O}_{3} / \mathrm{CO}_{3} \mathrm{O}_{4} / \mathrm{SPE}$ in $0.1 \mathrm{MPBS}(\mathrm{pH}$ 7.0) containing $500.0 \mu \mathrm{M}$ CA at various scan rates $\left(10,20,30,40,50,60,70,80,90\right.$ and $\left.100 \mathrm{mV} \mathrm{s}^{-1}\right)$. Inset: Variation of anodic peak current vs. $v^{1 / 2}$. 


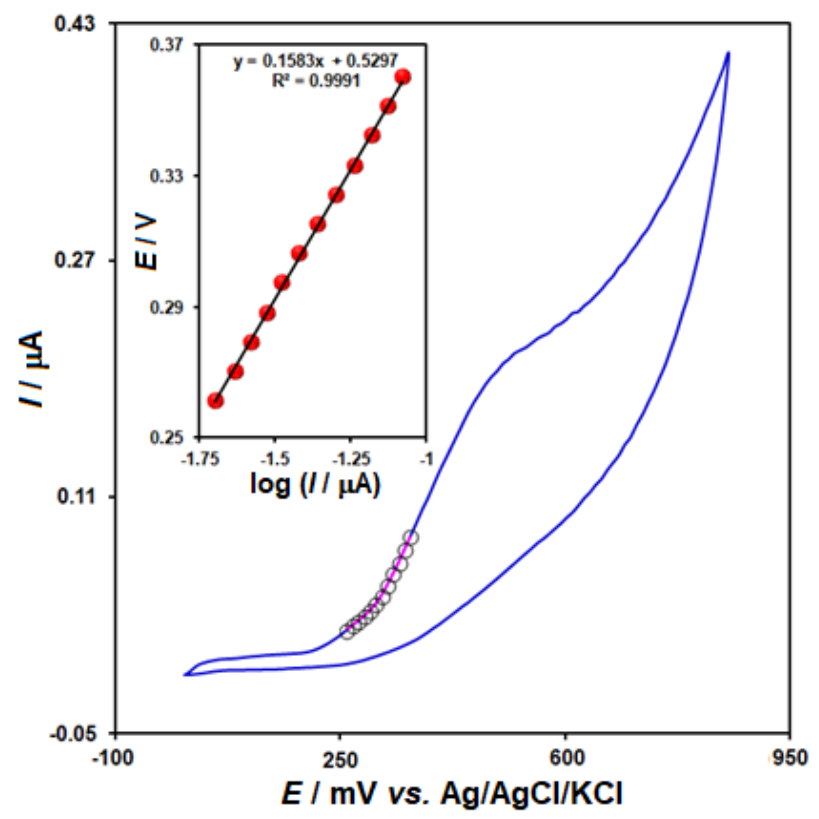

Fig. 6. $\mathrm{CV}$ for $\mathrm{La}_{2} \mathrm{O}_{3} / \mathrm{CO}_{3} \mathrm{O}_{4} / \mathrm{SPE}$ in $0.1 \mathrm{MPBS}\left(\mathrm{pH}\right.$ 7.0) with a scan rate of $10 \mathrm{mV} \mathrm{s}^{-1}$ in the presence of 500.0 $\mu M C A$. The inset shows the Tafel plot derived from the CV.

\section{Chronoamperometric investigation}

Chronoamperometric measurements of carvacrol at $\mathrm{La}_{2} \mathrm{O}_{3} / \mathrm{CO}_{3} \mathrm{O}_{4} / \mathrm{SPE}$ were carried out by setting the working electrode potential at $0.5 \mathrm{~V} v s$. $\mathrm{Ag} / \mathrm{AgCl} / \mathrm{KCl}(3.0 \mathrm{M})$ for various concentrations of carvacrol in PBS ( $\mathrm{pH} \mathrm{7.0)}$ and the results are shown in Figure 7. The determination of diffusion coefficient for electroactive moieties (carvacrol in this case) with a diffusion coefficient of $D$, is performed using the Cottrell equation [44] which under the mass transport limited condition is defined as:

$I=\mathrm{n} F A D^{1 / 2} C_{\mathrm{b}} \pi^{-1 / 2} t^{-1 / 2}$

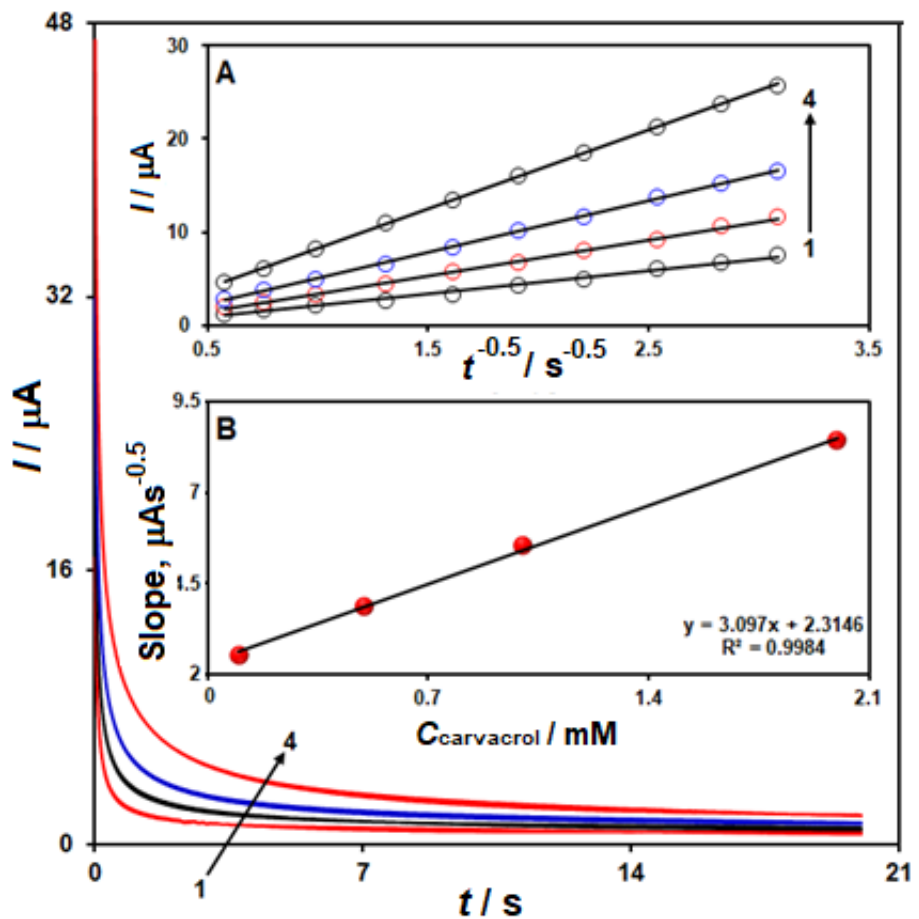

Fig. 7. Chronoamperograms of $\mathrm{La}_{2} \mathrm{O}_{3} / \mathrm{CO}_{3} \mathrm{O}_{4} / \mathrm{SPE}$ in $0.1 \mathrm{M} \mathrm{PBS}(\mathrm{pH}$ 7.0) for different concentrations of CA. The numbers 1-4 correspond to 0.1, 0.5, 1.0 and 2.0 mM of CA. Insets: (A) Plots of I vs. $t^{-1 / 2}$ obtained from chronoamperograms. (B) Plot of the slope of straight lines against CA concentration. 
In eq. (2), $\mathrm{n}, A, D$ and $C_{\mathrm{b}}$ are number of transferred electrons, electrode area $\left(\mathrm{cm}^{2}\right)$, diffusion coefficient $\left(\mathrm{cm}^{2} \mathrm{~s}^{-1}\right)$ and bulk concentration of electroactive species $\left(\mathrm{mol} \mathrm{cm}^{-3}\right)$, respectively. Experimental plots of $I$ vs. $t^{-1 / 2}$ are for various concentrations of carvacrol presented in Figure 7A, while slopes of the resultant straight lines are plotted versus carvacrol concentrations in Figure 7B. From the resultant slope and the Cottrell equation, the mean value of $D$ for carvacrol was determined as $3.3 \times 10^{-6} \mathrm{~cm}^{2} \mathrm{~s}^{-1}$.

\section{The working curve and detection limit}

The higher sensitivity of pulse techniques with respect to $\mathrm{CV}$ is due to the reduction of charging currents. The electro-oxidation peak current of acetyl carvacrol at the surface of $\mathrm{La}_{2} \mathrm{O}_{3} / \mathrm{CO}_{3} \mathrm{O}_{4} / \mathrm{SPE}$ can be used to determine carvacrol in the solution. Due to the higher sensitivity and better performance of DPV in analytical applications, DPV experiments were carried out using $\mathrm{La}_{2} \mathrm{O}_{3} / \mathrm{CO}_{3} \mathrm{O}_{4} / \mathrm{SPE}$ in $0.1 \mathrm{M}$ $\mathrm{PBS}(\mathrm{pH}=7.0)$ containing various concentrations of carvacrol. The results shown in Figure 8 reveal that at the surface of $\mathrm{La}_{2} \mathrm{O}_{3} / \mathrm{CO}_{3} \mathrm{O}_{4} / \mathrm{SPE}$, there is a linear dependency between electrocatalytic peak currents of carvacrol oxidation and its concentration within the range of $10.0-800.0 \mu \mathrm{M}$. The correlation coefficient is 0.9998 , and the detection limit $(3 \sigma)$ was obtained as $1.0 \mu \mathrm{M}$.

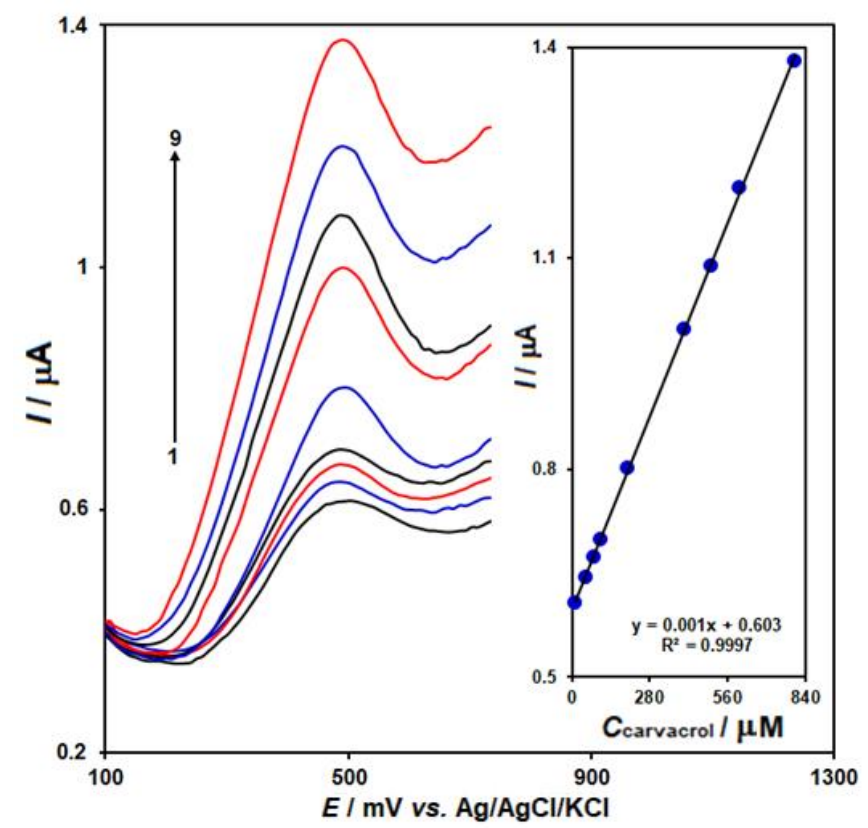

Fig. 8. DPVs of $\mathrm{La}_{2} \mathrm{O}_{3} / \mathrm{CO}_{3} \mathrm{O}_{4} / \mathrm{SPE}$ in $0.1 \mathrm{MPBS}(\mathrm{pH}$ 7.0) containing different concentrations of CA (10.0, 50.0, 75.0, 100.0, 200.0, 400.0, 500.0, 600.0 and 800.0 $\mu \mathrm{M})$. Inset: Plot of I vs. $C A$ concentrations. Scan rate $=50 \mathrm{mV} \mathrm{s}^{-1}$.

\section{Interference studies}

The influence of various substances as compounds potentially interfering with the determination of carvacrol was studied under optimum conditions. The potentially interfering substances were chosen from the group of substances commonly found with carvacrol in pharmaceuticals and/or biological fluids. The tolerance limit was defined as the maximum concentration of the interfering substance that caused the error less than $\pm 5 \%$ in the determination of carvacrol. According to the results, I-lysine, glucose, NADH, acetaminophen, uric acid, I-asparagine, I-serine, I-threonine, I-proline, I-histidine, I-glycine, I-phenylalanine, lactose, saccarose, fructose, benzoic acid, methanol, ethanol, urea, caffeine, dopamine, epinephrine, norepinephrine, serotonin, ascorbic acid, isoproterenol, levodopa, carbidopa, $\mathrm{Mg}^{2+}, \mathrm{Al}^{3+}, \mathrm{NH}_{4}{ }^{+}, \mathrm{Fe}^{+2}, \mathrm{Fe}^{+3}, \mathrm{~F}^{-}, \mathrm{SO}_{4}{ }^{2-}$ and $\mathrm{S}^{2-}$ did not show interference in the determination of carvacrol. 


\section{The repeatability and stability of $\mathrm{La}_{2} \mathrm{O}_{3} / \mathrm{CO}_{3} \mathrm{O}_{4} / \mathrm{SPE}$}

The generation of reproducible surface of $\mathrm{La}_{2} \mathrm{O}_{3} / \mathrm{CO}_{3} \mathrm{O}_{4} / \mathrm{SPE}$ was examined by CVs data obtained in $0.1 \mathrm{M} \mathrm{PBS}(\mathrm{pH} 7.0)$ containing CA. The calculated RSD for various parameters was accepted as the criteria for satisfactory surface reproducibility (2-4 \%). This degree of reproducibility is virtually the same as that expected for the renewal of ordinary screen-printed electrode surface. In addition, the long-term stability of $\mathrm{La}_{2} \mathrm{O}_{3} / \mathrm{CO}_{3} \mathrm{O}_{4} / \mathrm{SPE}$ was tested over 3-week period. When $\mathrm{CV}$ s were recorded after the modified electrode was stored in atmosphere at room temperature, the peak potential for carvacrol oxidation was unchanged and the current signals showed less than $2.7 \%$ decrease of the initial response. The antifouling properties of modified electrode towards carvacrol oxidation and its oxidation products were investigated by recording the CVs of modified electrode before and after using in the presence of carvacrol. CVs were recorded in the presence of carvacrol for 20 cycles at a scan rate $50 \mathrm{mV} \mathrm{s}^{-1}$. The peak potentials were unchanged, and the currents decreased by less than $3.9 \%$. Therefore, at the surface of $\mathrm{La}_{2} \mathrm{O}_{3} / \mathrm{CO}_{3} \mathrm{O}_{4} / \mathrm{SPE}$, not only the sensitivity increase, but the fouling effect of the carvacrol and its oxidation product also decreases. However, we regenerated the surface of $\mathrm{La}_{2} \mathrm{O}_{3} / \mathrm{CO}_{3} \mathrm{O}_{4} / \mathrm{SPE}$ before each experiment.

\section{Analysis of real samples}

The analytical practicality of the proposed method was evaluated through the quantification of carvacrol in urine samples by using the standard addition method. The outcomes for the carvacrol determination in real samples are presented in Table 1. The experimental results showed acceptable recoveries for carvacrol. The reproducibility of the method was investigated by the mean relative standard deviation (RSD).

Table 1. Determination of carvacrol in urine samples ( $n=5)$ using $\mathrm{La}_{2} \mathrm{O}_{3} / \mathrm{CO}_{3} \mathrm{O}_{4} / \mathrm{SPE}$.

\begin{tabular}{cccc}
\hline Spiked concentrations, $\mu \mathrm{M}$ & Found concentrations, $\mu \mathrm{M}$ & Recovery, $\%$ & $\mathrm{RSD}, \%$ \\
\hline 0 & - & - & - \\
\hline 7.5 & 7.6 & 101.3 & 1.8 \\
\hline 12.5 & 12.4 & 99.2 & 2.1 \\
\hline 17.5 & 17.3 & 98.8 & 3.1 \\
\hline 22.5 & 22.7 & 100.9 & 2.7 \\
\hline
\end{tabular}

\section{Conclusions}

For the first time, $\mathrm{La}_{2} \mathrm{O}_{3} / \mathrm{CO}_{3} \mathrm{O}_{4}$ nanocomposite modified-SPE demonstrates an outstanding behavior toward carvacrol oxidation in an aqueous PBS ( $\mathrm{pH} 7.0)$ solution. Based on the electrochemical oxidation, the quantitative measurement of carvacrol in real samples was developed by a simple, rapid, selective and sensitive DPV technique. In the DPV determination, the detection limit of carvacrol was estimated as $1.0 \mu \mathrm{M}$. The developed method is reproducible and reliable. Good reproducibility of the modified electrode suggests application of the method in the routine analysis of carvacrol-containing samples.

\section{References}

[1] N. Gavaric, S. Smole Mozina, N. Kladar, B. Bozin, Journal of Essential Oil Research 18 (2015) 1013-1021.

[2] V. Kiyanpour, A. R. Fakhari, R. Alizadeh, B. Asghari, M. Jalali-Heravi, Talanta 79 (2009) 695-699.

[3] W. X. Du, C. E. Olsen, R. J. Avena Bustillos, T. H. McHugh, C. E. Levin, M. Friedman, Journal of Agricultural and Food Chemistry 56 (2008) 3082-3088.

[4] S. Adams, B. Kunz, M. Weidenbörner, Journal of Essential Oil Research 8 (1996) 535-540.

[5] H. Hajimehdipoor, M. Shekarchi, M. Khanavi, N. Adib, M. A. Amri, Pharmacognosy Magazine 6 (2010) 154-158.

[6] H. Sereshti, Y. Izadmanesh, S. Samadi, Journal of Chromatography A 1218 (2011) 4593-4598. 
[7] A. Rančić, M. Soković, J. Vukojević, A. Simić, P. Marin, S. Duletić-Laušević, D. Đoković, Journal of Essential Oil Research 17 (2005) 341-345.

[8] C. Kohlert, G. Abel, E. Schmid, M. Veit, Journal of Chromatography B 767 (2002) 11-18.

[9] A. Bazylko, H. Strzelecka, Chromatographia 52 (2000) 112-114.

[10] M. Lodesani, A. Pellacani, S. Bergomi, E. Carpana, T. Rabitti, P. Lasagni, Apidologie 23 (1992) 257-272.

[11] P. Vinas, M. J. Soler-Romera, M. Hernandez-Cordoba, Talanta 69 (2006) 1063-1067.

[12] E. Herrero-Hernandez1, R. Carabias-Martinez, E. Rodriguez-Gonzalo, Analytica Chimica Acta 650 (2009) 195-201.

[13] M. Mazloum-Ardakani, H. Beitollahi, B. Ganjipour, H. Naeimi, International Journal of Electrochemical Science 5 (2010) 531-546.

[14] G.O. Buica, L.G. Lazar, E. Saint-Aman, V. Tecuceanu, C. Dumitriu, I.A. Anton, A.B. Stoian, E.M. Ungureanu, Sensors \& Actuators, B: Chemical 246 (2017) 434-443.

[15] S. A. Mozaffari, R. Rahmanian, M. Abedi, H. S. Amoli, Electrochimica Acta 146 (2014) 538-547.

[16] H. Beitollahi, I. Sheikhshoaie, International Journal of Electrochemical Science 7 (2012) 7684-7698.

[17] H. Karimi-Maleh, M. Moazampour, H. Ahmar, H. Beitollahi, A. A. Ensafi, Measurement 51 (2014) 9199.

[18] R. Rahmanian, S. A. Mozaffari, Sensors \& Actuators, B: Chemical 207 (2015) 772-781.

[19] S. M. A. Shibli, K. S. Beenakumari, N. D. Suma, Biosensors \& Bioelectronics 22 (2006) 633-638.

[20] E. Molaakbari, A. Mostafavi, H. Beitollahi, Sensors \& Actuators, B: Chemical 208 (2015) 195-203.

[21] J. P. Metters, R. O. Kadara, S. E. Banks, Analyst 136 (2011) 1067-1076.

[22] H. Heli, M. Hajjizadeh, A. Jabbari, A. A. Moosavi-Movahedi, Biosensors \& Bioelectronics 24 (2009) 23282333.

[23] H. Heli, S. Majdi, N. Sattarahmady, Sensors \& Actuators, B: Chemical 145 (2010) 185-193.

[24] S. Tajik, M.A. Taher, H. Beitollahi, Journal of Electroanalytical Chemistry 704 (2013) 137-144.

[25] S. Z. Mohammadi, E. Reiahipour, F. Mosazadeh, Analytical and Bioanalytical Electrochemistry 10 (2018) 383-393.

[26] E. H. Bindewald, A. F. Schibelbain, A. P. Papi, E. G. C. Neiva, A. J. G. Zarbin, M. F. Bergamini, L. H. Marcolino-Júnior, Materials Science \& Engineering C-Materials for Biological Applications 79 (2017) 262-269.

[27] K. Chu, F. Wang, X. Zhao, X. Wang, Y. Tian, Materials Science \& Engineering C-Materials for Biological Applications 81 (2017) 452-458.

[28] S. Z. Mohammadi, H. Beitollahi, E. Bani Asadi, Environmental Monitoring Assessment 187 (2015) 122132.

[29] C. Wei, M. Yang, J. Hu, Q. Li, Analytical Letters 40 (2007) 3182-3194.

[30] H. Yaghoubian, Sh. Jahani, H. Beitollahi, S. Tajik, R. Hosseinzadeh, P. Biparva, Journal of Electrochemical Science and Technology 9 (2018) 109-117.

[31] S. Z. Mohammadi, A. H. Sarhadi, F. Mosazadeh, Analytical and Bioanalytical Chemistry Research 5 (2018) 363-372.

[32] I. Streeter, G. G. Wildgoose, L. Shao, and R. G. Compton, Sensors \& Actuators, B: Chemical 133 (2008) 462466.

[33] S. Z. Mohammadi, H. Beitollahi, M. Hassanzadeh, Analytical and Bioanalytical Chemistry Research 5 (2018) 55-65.

[34] S. Z. Mohammadi, H. Beitollahi, N. Nikpour, R. Hosseinzadeh, Analytical and Bioanalytical Chemistry Research 3 (2016) 187-194.

[35] H. Mahmoudi Moghaddam, H. Beitollahi, S. Tajik, I. Sheikhshoaie, P. Biparva, Environmental Monitoring and Assessment 187 (2015) 407-418.

[36] S. Z. Mohammadi, H. Beitollahi, M. Mousavi, Russian Journal of Electrochemistry 53 (2017) 374-379.

[37] X. Chen, J. Zhu, Z. Chen, C. Xu, Y. Wang C. Yao, Sensors \& Actuators, B: Chemical 159 (2011) 220-228.

[38] R. L. Doyle, M. E. G. Lyons, Electrocatalysis 5 (2014) 114-124.

[39] F. Soofiabadi, A. Amiri, Sh. Jahani, Analytical and Bioanalytical Electrochemistry 9 (2017) 340-350.

[40] H. Jo, J. Her, H. Lee, Y. B. Shim, C. Ban, Talanta 165 (2017) 442-448.

[41] F. Khosrow-pour, M. Aghazadeh, B. Sabour, S. Dalvand, Ceramics International 39 (2013) 9491-9498.

[42] F. L. S. Carvalho, Y. J. O. Asencios, A. M. B. Rego, E. M. Assaf, Applied Catalysis A: General 483 (2014) 5262. 
[43] Y. Xu, Y. Peng, X. Zheng, K. D. Dearn, H. Xu, X. Hu, Energy 83 (2015) 80-88.

[44] A. J. Bard, and L. R. Faulkner, Electrochemical Methods Fundamentals and Applications, Second ed., Wiley, New York (2001).

(C)2019 by the authors; licensee IAPC, Zagreb, Croatia. This article is an open-access article distributed under the terms and conditions of the Creative Commons Attribution license (http://creativecommons. org/licenses/by/4.0/) 